\title{
An Exploratory Study of Live vs. Web-Based Delivery of a Phlebotomy Program
}

\author{
NADINE A FYDRYSZEWSKI, CRAIG SCANLAN,H JESSE GUILES, ANN TUCKER
}

\begin{abstract}
Changes in student population and increased Web-based education offerings provided the impetus to assess pedagogy, cognitive outcomes and perceptions of course quality.
\end{abstract}

OBJECTIVE: This study explored cognitive outcomes and students' perception of course quality related to the Seven Principles for Good Practice in Undergraduate Education between live classroom delivery, compared to a Web-based delivery of a phlebotomy program.

DESIGN: Quasi-experimental; students self-selected to enroll in live or Web-based program.

RESULTS: For cognitive outcomes, no significant difference was found between the groups. Student perception of course quality differed only for Principle One (student-instructor contact). Students in the live classroom rated Principle One higher for the Part I course compared to the Web-based group. For the Part II course, there was no significant difference in perception of course quality related to any of the Seven Principles.

CONCLUSIONS: The more constructivist pedagogy in the Part II course did not improve cognitive outcomes however, it may have contributed to knowledge retention. The live group rated Principle One in the Part II course evaluation relatively the same as they did for the Part I course evaluation. However, the Web-based group rated Principle One considerable higher for the Part II course than for Part I course. Future studies with a larger sample could explore improved course quality assessment instruments.

INDEX TERMS: Web-based education, cognitive outcomes, course quality, Seven Principles

Clin Lab Sci 2010;23(3)Suppl:3-39
Nadine A. Fydryszewski, PhD, MLS, Dept. of Clinical Laboratory Sciences, University of Medicine \& Dentistry of New Jersey, Newark, NJ 07101

Craig Scanlan, EdD, RT, Dept. of Primary Care, University of Medicine \& Dentistry of New Jersey, Newark, NJ 07101

H. Jesse Guiles, EdD, MLS, Dept. of Clinical Laboratory Sciecnes, University of Medicine \& Dentistry of New Jersey, Newark, NJ 07101

Ann W. Tucker, DEd, RDH, Dept of Interdisciplinary Studies, University of Medicine \& Dentistry of New Jersey, Newark, NJ 07101

Address for Correspondence: Nadine A, Fydryszewski, PhD, MLS, University of Medicine \& Dentistry of New Jersey, 65 Bergen Street-SSB GB 20, Newark, NJ 07101, 973-972-5089,fydrysna@umdnj.edu

\section{INTRODUCTION}

The $21^{\text {st }}$ century has introduced unique challenges to higher education. A changing student population with increased non-traditional students, women, adult learners ${ }^{1}$, rapid technological advances, ${ }^{2}$ and increased competition and challenges in resource allocation ${ }^{3}$ have compelled higher education institutions to become more responsive to the needs of adult learners. An analysis of trends revealed that there is a growing market for distance education courses both academic and non-academic as well as certificate programs. ${ }^{4,5}$ In the clinical laboratory science profession, an increasing number of programs are offering Web-based education, ${ }^{6}$ but a paucity of literature exists regarding the evaluation of clinical laboratory science Web-based programs and courses. 


\section{RESEARCH AND REPORTS}

The purpose of this study was to compare two types of educational delivery methods for a post-secondary phlebotomy certificate program, Web-based distance learning, and traditional live classroom delivery. The phlebotomy program consisted of theoretical courses and a clinical practicum. The instructional design was a mixed pedagogical design based on the Continuum of Knowledge Acquisition Model (CKAM). ${ }^{7}$

\section{Pedagogy - CKAM}

The CKAM advocates a mixed pedagogical approached based upon the level of the learner and the pedagogical strategies change as the student moves along the continuum of learning. ${ }^{7,89}$ This approach supports the concept of matching learning theories with the content and the level of the learner, blending objectivist and constructivist learning theory, and is divided into three phases. In the first phase (introductory), the learner has very little or no prior knowledge of the subject matter. In this initial stage of learning an objectivist approach is used to learning strategies. Objectivist pedagogy is instructor-centered, using clearly defined measurable goals and mainly utilizing testing, reinforcement, retesting strategies to assess learning. ${ }^{10,11}$ In the second phase (advanced), the learner has acquired some knowledge and is capable of solving more complex problems. In this phase, constructivist pedagogy is introduced. Constructivist strategies are learnercentered, with the instructor involved as a facilitator and utilizes problem solving approaches as well as strategies where the student helps create their learning environment. ${ }^{12}$ By the third phase (expert), learners should have extensive knowledge and experience that has been transferred from the previous learning phases. In the CKAM Model, as a student moves through the phases of learning they gain more control over their learning and the learning environment.

The mixed model has application in health professions education, particularly phlebotomy education. Students entering the health professions usually have minimal to no prior knowledge of the discipline-specific content and skills. The educational process begins with building a foundation of knowledge using the objectivist approach, and progresses toward higher-level knowledge acquisition, skill building, and experiential learning in advanced theory courses and the clinical practicum using a constructivist approach.

This research focused on student learning outcomes measured by final exam performance and perceptions of course quality measured by a Course Quality Survey. The research addressed several shortcomings and gaps cited by Phipps and Merisotis ${ }^{13}$ as key deficiencies in past studies: 1) the theoretical/conceptual framework of distance education courses, 2) program outcomes versus single course outcomes, 3) instrument validation, and 4) sample selection. In addition, this study identified and evaluated strategies developed for both the Webbased and traditional live classroom phlebotomy program that implemented the Seven Principles for Good Practice in Undergraduate Education. ${ }^{14,15,16}$ Table 1 lists the Seven Principles.

Table 1. Seven Principles for Good Practice in Undergraduate Education

\begin{tabular}{ll}
\hline Principle & \multicolumn{1}{c}{ Description } \\
One & Encourages contact between students and instructor \\
Two & Develops reciprocity and cooperation among students \\
Three & Uses active learning techniques \\
Four & Gives prompt feedback \\
Five & Emphasizes time on task \\
Six & Communicates high expectations \\
Seven & Respects diverse talents and ways of learning \\
& \\
Adapted from "Seven Principles for Good Practice in Undergraduate \\
Education", by Chickering A, Gamson Z. 1987, AAHE Bulletin, March, p.1
\end{tabular}

The hypotheses explored were: 1) is there a difference in cognitive outcomes between students learning theoretical content in a traditional synchronous live classroom format compared to those learning the same content in an asynchronous Web-based delivery format? 2) is there a difference in student perception of the course quality related to the Seven Principles in a traditional synchronous live classroom format compared to an asynchronous Web-based delivery format? 3) is there a difference in student cognitive outcomes versus student perception of course quality in a traditional synchronous live classroom format compared to an asynchronous Web-based delivery format?

The Course Quality Survey was developed using items from the Flashlight Current Student Inventory (CSI). CSI 


\section{RESEARCH AND REPORTS}

is an evaluation tool kit consisting of 481 survey items and interview questions indexed by technology and educational issues based on 14 themes. The 14 themes incorporate and expand on the Seven Principles. ${ }^{17}$ IRB approval was obtained from the institution and data from only those students who signed the consent form were used in the study.

\section{METHODS}

The Phlebotomy Program used in this study consists of multiple courses: Part I Basic Theory, Part II Advanced Theory, and a Clinical Practicum. The research was conducted in three phases. Curriculum design was the focus in phase one. In this phase, the CKAM was operationalized, and the Seven Principles (Table 1) were implemented into the courses. Pilot testing of the curriculum and the validation of instruments was conducted in phase two, and phase three was implementation of the research study.

Research design was quasi-experimental, with students self-selecting to enroll in the live or Web-based program. The independent variable was the delivery method, live vs. Web. Only the delivery method varied, and every efforts was made to assure the education experience was the same for both groups. The dependent variables were Comprehensive Exam Scores and Course Quality Survey Scores taken at two intervals after the Part I and Part II courses. Since a true experimental design with random selection could not be achieved in this study, a Pre-Course survey was administered to explore potential covariates to see if they might confound the effect of the educational delivery method on the outcomes.

Instrument validity and reliability for the Comprehensive Exam was assessed using program historical data. Content validity was validated by national expert review, adhering to NAACLS Standards, and ASCP-BOR National Certification Exam question matrix. Reliability analysis yielded a Cronbach's alpha of .86, indicating an overall scale that was highly reliable. Correlation analysis of the Comprehensive Exam to the ASCP National Certification Exam was moderate-strong correlation $(r=.705, p=<.01)$. Items for the Course Quality Survey were selected from the Current Student Inventory (CSI) of the Flashlight
Project, and this item pool is coded to align with the Seven Principles. Survey items were selected to assess each of the Seven Principles. Content validity was conducted by the Flashlight Project. The research study survey reliability was assessed via a pilot study and yielded an overall scale that was highly reliable (.83). The research study data showed an overall high reliability (.90).

Sample size was determined by an a prior power analysis (0.8) indicating a minimum of 17 in each group. Due to attrition this was not achieved in the 2005-2006 offering of the program. Data were pooled to include the 2006-2007 class. A pre-course survey was administered to assess key sample demographics and to gather data on the potential covariates. The characteristics assessed were: age, gender, ethnicity, English as a second language, work status, highest level of education, length of time since took a formal education course, reasons for taking this program, residence (urban vs suburban), and prior phlebotomy training/experience.. Analysis of the demographics between the 05/06 and 06/07 groups indicated no significant difference. Post hoc power analysis was 0.72 .

\section{DATA ANALYSIS \& RESULTS}

Data analysis consisted of descriptive statistics, chisquare, independent t-test, correlation analysis. All methodological assumptions were met except random samples, which could limit the generalization of the study. For the t-test, homogeneity of variances was confirmed by the Levene's Test for Equality of Error Variances. For the Pearson product-moment correlation analysis, all distributions were confirmed to be normal by the Shapiro-Wilk Test.

\section{Sample}

A total of 62 students enrolled: 33 in the live program; 29 in the Web-based program; 58 signed the consent form to participate in the study. The final study sample, those completing the phlebotomy program, was 30, with 19 in the live and 11 in the Web-based program. For demographic characteristics, there was no significant difference between the program completers vs. the non-completers, except for ethnicity. A slightly higher rate (50\%) of African-American/Blacks did not complete the program. For the program completers 


\section{RESEARCH AND REPORTS}

there was no significant difference between the two groups for any of the demographic characteristics explored except for education level. There was a significant relationship between the type of education delivery and the highest education level of the student. In the Web-based group 64\% indicated more than a high school education, while only $16 \%$ of those enrolled in the live classroom program achieved more than a high school education. An independent sample ttest was performed to assess computers skills between the two groups. There was no significant difference between the live classroom setting and the Web-based setting for computer skills $(\mathrm{t}=.796, d f-25, p=.43)$.

\section{Cognitive Scores}

Independent samples t-test was used to compare cognitive outcomes between the live and Web-based groups (Table 2).

Table 2. Independent Samples t-test - Cognitive Scores

\begin{tabular}{lccc}
\hline & N & M & SD \\
Part I Exam Scores & & & \\
Live Classroom & 19 & 88.79 & 7.40 \\
Web-based & 11 & 87.27 & 5.73 \\
Part II Exam Scores & & & \\
Live Classroom & 19 & 85.32 & 8.45 \\
Web-based & 11 & 87.09 & 9.98 \\
\hline
\end{tabular}

The same final exam was administered at the end of the Part I and Part II course. There was no significant difference between the live classroom group and the Web-based group for the first administration at the end of the Part I course $(\mathrm{t}=-.57, d f=28, p=.57)$, and no significant difference between the two groups for the second administration at the end of the Part II course $(\mathrm{t}=-.52, d f=28, p=.61)$.

\section{Student Perception of Course Quality Ratings}

Independent samples t-test was used to compare students' perception of course quality between the live and Web-based groups. The same Course Quality Survey was administered at the end of the Part I and Part II course. There was no significant difference between the live classroom and the Web-based groups for the overall Course Quality Survey rating for the first administration at the end of the Part I course $(t=78$, $d f=28, p=.44)$ and no significant difference for the second administration at the end of the Part II course $(\mathrm{t}=.58, d f=28, p=.57)$. For the survey results from the Part I course, there was no significant difference for Principles Two through Principle Seven. However, there was a significant difference between the live classroom setting and the Web-based classroom setting for Principle One, student/instructor contact, $(t=2.34$, $d f=28, p=.03)$. Those in the live classroom setting had significantly higher Principle One ratings than those in the Web-based classroom setting. For the survey results from the Part II course there was no significant difference between the Web-based classroom setting and the live classroom setting for any of the Seven Principles subscales.

A paired sample t-test was conducted to evaluate the Part I and Part II Course Quality Survey Principle One (student/instructor contact) subscale rating differences between the live classroom group and the Web-based group. There was no significant difference between Part I and Part II course rating of Principle One (student/instructor contact) for the live setting $(\mathrm{t}=-1.42$, $d f=18, p=.17)$, and no significant difference between Part I and Part II course rating of Principle One (student/ instructor contact) for the Web-based group $(t=-2.08, d f=10, p=.06)$. Evaluating the mean difference for Principle One (student/instructor contact) for the Part I and the Part II course revealed the live classroom group rated Principle One (student/instructor contact) slightly higher for the Part II course than the rating for the Part I course (mean difference $=-1.37, S D=4.20$ ). This is a difference of approximately one point and of little significance. For the Web-based group, the mean difference for Principle One (student/instructor contact) was $-4.27, S D=6.82$. The Web-based group demonstrated a four point increase in the rating of Principle One (student/instructor contact) between the Part I course $(M=41.90)$ and the Part II course $(M=46.18)$. Although the difference is statistically not significant, a wide $95 \%$ confidence interval of difference $(-8.86)$ and the small sample for the Web-based group $(\mathrm{n}=11)$ suggests the need to collect additional data before making any conclusive observations.

Pearson's correlation coefficients were calculated to determine whether there was a correlation between the 


\section{RESEARCH AND REPORTS}

Course Quality Survey scores and the cognitive Examination scores. For the Part I course, all of the correlations between the Course Quality Survey ratings and the cognitive measurement, the final exam score were significant and negative. These results reveal that, in general, the higher a students' cognitive score the lower their overall course quality and principle subscale scores. When examining the correlations from the Part II course, all of the correlations between the Course Quality Survey ratings and the cognitive measurement, the final exam scores were not significant.

\section{DISCUSSION}

Analysis revealed there was no significant difference between the two groups for age, gender, ethnicity, English language, work status, reasons for taking the course, residence, prior phlebotomy training and computer skills. However, there was a significant relationship between the type of education delivery and the education level of the student. Although the groups differed in highest level of education, statistical analysis failed to show that this difference affected students' cognitive examination scores. Since there was no effect on this outcome measure, there was no justification to incorporate education level as a covariate.

There was no significant difference in scores between the live classroom and the Web-based classroom setting for the first administration of the final exam in the Part I course and the second administration in the Part II course. These findings were consistent with the numerous studies that have reported Web-based student cognitive outcomes to be comparable to traditional live classroom delivery. ${ }^{18,19,20}$ Because the study's planned minimum power was not achieved, a Type II error due to inadequate sample size may be a factor in the no significant difference findings for cognitive outcomes. However, the difference between the groups on the final exam scores was extremely small, on average less than two points. This difference is not seen as particularly important, and an adequately powered study still may not have found this difference statistically significant. Based on the results of this study it is apparent that the mixed pedagogical approach implemented, particularly the more constructivist approach in the Part II course, did not improve cognitive examination scores. Students performed relatively the same, with no significant increase or decrease in final exam scores between the Part I and Part II course.

There was no significant difference between the live classroom and Web-based groups for the overall course quality ratings for the Course Quality Survey in Part I and Part II courses. However, the findings revealed a significant difference for subscale Principle One (student-instructor contact). The results of the Course Quality Survey administered in the Part I course revealed students in the live classroom rated their experience significantly higher on Principle One subscale (student-instructor contact) when compared to students in the Web-based classroom. This was not the case for the rating results of the second administration of the Course Quality Survey for the Part II course. For the Part II course, there was no significant difference between the live classroom setting and the Web-based setting for the overall Course Quality rating and all the subscales. Even after controlling for differences in final exam grades, the students in the live setting vs. the Web-based groups still differed significantly $(\mathrm{F}=5.25, d f=1,27, p=0.30) \quad$ in their perception of Principle One (student-instructor contact). This means that two students with the same grades still rated Principle One (student-instructor contact) differently. Possible explanations for this finding may be the physical/emotional presence in live vs Web delivery, instructor attributes and role in communication, and the student's role in communication. Further studies are needed to explore these potential variables and their impact on perception of course quality. In the assessment of the sample characteristics, there was a difference between the live and Web-based groups in level of education. The results revealed that a higher portion of students with post-high school education were in the Web-based group. In general, for the first administration of the Course Quality Survey in the Part I course, the results indicated that those students with only a high school education rated the course higher than those with more than high school education. This suggests that the education level may be a third variable influencing the correlation analysis.

For the Part II course, there was no significant difference between the live classroom setting and the Web-based setting for overall Course Quality Survey 


\section{RESEARCH AND REPORTS}

ratings and all the subscales. It appeared that the difference in the rating of Principle One (studentinstructor contact) between the first administration in the Part I course and the second administration in the Part II course were related to the Web-based group rating Principle One (student-instructor contact) higher for Part II course. In contrast, the traditional live classroom group provided comparable ratings on Principle One (student-instructor contact) between the first and second survey administration. This increase in the Web-based group rating of Principle One (studentinstructor contact) may have been due to the clinical rotation experience. The Web-based group experienced live student-instructor/preceptor interaction for the first time during the program of study.

For the Part I course, all correlations between the Course Quality Survey's seven subscales and the students' examination scores were significant and negative. Contrary to expectations, this finding indicated that the best performing students tended to assign lower ratings to all dimensions of course quality. In contrast the weaker students, although still passing the course, tended to rate the course higher. Complicating this unexpected finding was that the same relationships did not pertain when comparing these measures for the Part II course. For the Part II course, the correlations between the Course Quality Survey and the cognitive measurement, although negative, were relatively low. In the Part II course, although all students began with didactic sessions and lab sessions, they were then placed in different clinical sites for the clinical practicum. There is clinical site rotation variability (i.e. site size, preceptor, patient population). These variables may have accounted for the changes in course perception observed in this study.

\section{CONCLUSIONS \& FUTURE DIRECTIONS}

Limitations applied to this study were: 1) small sample size which limits generalization; 2) quasi-experimental vs. true experimental design; 3) construction of the Course Quality Survey may not have included all measures associated with good practice and selfperception of course quality and as applied in this analysis, several of the survey's Principle sub-scales had marginal reliability; 4) the effect of student learning styles on outcomes which was beyond the scope of this study. Notwithstanding these limitations, the results of this study have both theoretical and practical implications. From a practical standpoint, the study revealed potential improvements that could be implemented in curriculum design, particularly related to the Part II course. The curriculum modifications could lead to an improved research design and potentially more meaningful findings. The comparison of outcomes in an entry-level allied health profession provided administrators and instructors with information to develop and evaluate similar programs that could be delivered in an on-line environment using a mixed pedagogical model.

The findings of this study provide several new lines of inquiry with future phlebotomy classes: 1) implementing modifications to improve measurement tools, 2) restructuring the program into three courses, Part I Theoretical, Part II Advanced Theoretical, and Part III Clinical Practicum, 3) evaluating the instructorstudent interaction in the Web-based courses and potential impact on perception of course quality, 4) assessment of student attributes, such as motivation and perseverance in relation to cognitive outcomes and perceptions of course quality and instructor effectiveness, 5) assessment of the applicability of the Seven Principles in a predominately objectivist pedagogical model versus a constructivist model, and 6) explore the role of education level on perceptions of course quality. Research can focus on the effectiveness of a mixed pedagogical approach such as the CKAM Model.

\section{REFERENCES}

1. National Center for Education Statistics. Distance education at degree-granting postsecondary institutions:2000-2001. 2003. Available from http://nces.ed.gov/pubsearch/pubsinfo.asp?pub id $=2003017$

2. Hosie P, Mazzarol T. Using technology for the competitive delivery of education services. Journal of Computer Assisted Learning. 2002. 15(2), 188-98.

3. Winston GC, Zimmerman DJ. Where is aggressive price competition taking higher education?. Change. 2000 Jul. Available from http://www.findarticles.com/p/articles/mi_m 1254/is_4_32/ai_64189897

4. National Center for Education Statistics. Distance education at degree-granting post secondary institutions: 2006-07. 2008. Available from http://nces.ed.gov/pubsearch/pubsinfo.asp?pub id $=2009044$ 


\section{RESEARCH AND REPORTS}

5. Allen E, Seaman J. Online nation: five years of growth in online learning. Needham, MA: The Sloan Consortium; 2007.

6. American Society for Clinical Laboratory Science \{Internet\}. Clinical laboratory science online directory. CLS and CLS graduate programs. 2008. Available from http://www.ascls.org/ leadership/sa/esa.asp

7. Jonassen DH, McAleese TMR, Duffy TM . A manifesto for a constructivist approach to technology in higher education. In Duffy, T.M., Lowyck, J., Jonassen, D.H., editors. The design of constructivist learning environments: implications for instructional design and the use of technology. Heidelburg, FRG: Springer-Verlag; 1993.

8. Jonassen DH. Objectivism versus constructivism: do we need a new philosophical paradigm?. Educational Technology: Research \& Development. 1991; 39 (3), 5-14.

9. Jonassen DH. Evaluating constructivist learning. Educational Technology. 1993; 31 (9), 28-33.

10. Ford, C.W. (Ed.). (1978). Clinical education for the allied health professions. St. Louis, Missouri: The C.V. Mosby Company.

11. Gage, N.L., \& Berliner, D.C. (1998). Educational psychology, $\sigma^{\text {th }}$ ed. Boston: Houghton-Mifflin.

12. Jonassen, D.H. (1999). Learning with technology: a constructivist perspective. Columbus, Ohio: Merrill/Prentice Hall.

13. Phipps R, Merisotis J. What's the difference? a review of contemporary research on the effectiveness of distance learning in higher education. Institute of Higher Education Policy. 1999. Washington, D.C.
14. Chickering AW, Gamson ZF. Seven principles for good practice in undergraduate education. AAHE Bulletin. 1987, March. Available from www.aahebulletin.com

15. Chickering AW, Gamson ZF. Applying the seven principles forgood practice in undergraduate education. San Francisco: Jossey-Bass, Inc.; 1991

16. Chickering AW, Erhamnn S. Implementing the seven principles: technology as a lever. American Association of Higher Education Bulletin, 1996 , p.3.

17. Ehrmann, S.C., \& Zuniga, R.E. (1997). The Flashlight Evaluation Handbook. Washington, D.C.: Teaching, Learning, and Technology Group.

18. Allen M, Mabry E, Mattrey M, Bourhis J, Titsworth S, et al. Evaluating the effectiveness of distance learning: a comparison using Meta-analysis. Journal of Communication. 2004; 54(3): 402-20.

19. Bearden E, Robinson, K, Deis M. A statistical analysis of dental hygiene students' grades in online and on-campus courses and performance on the national board dental hygiene examinations. The Journal of Dental Hygiene. 2002; 76 (3): 213-17.

20. Buchanan E, Brown M, Casanova J, Wolfram D, Xie H. (2000). Web based and traditional instruction: a systemic study of student and instructor perceptions from a graduate MLIS program. Teaching with Technology Today, 2000: 7(1). Available from:htpp:www.uwsa.edu/ttt/articles/Buchanan.htm.

21. American Council on Education. Adult learners in the United States: a national profile. 2006. Available from www.acenet. edu.

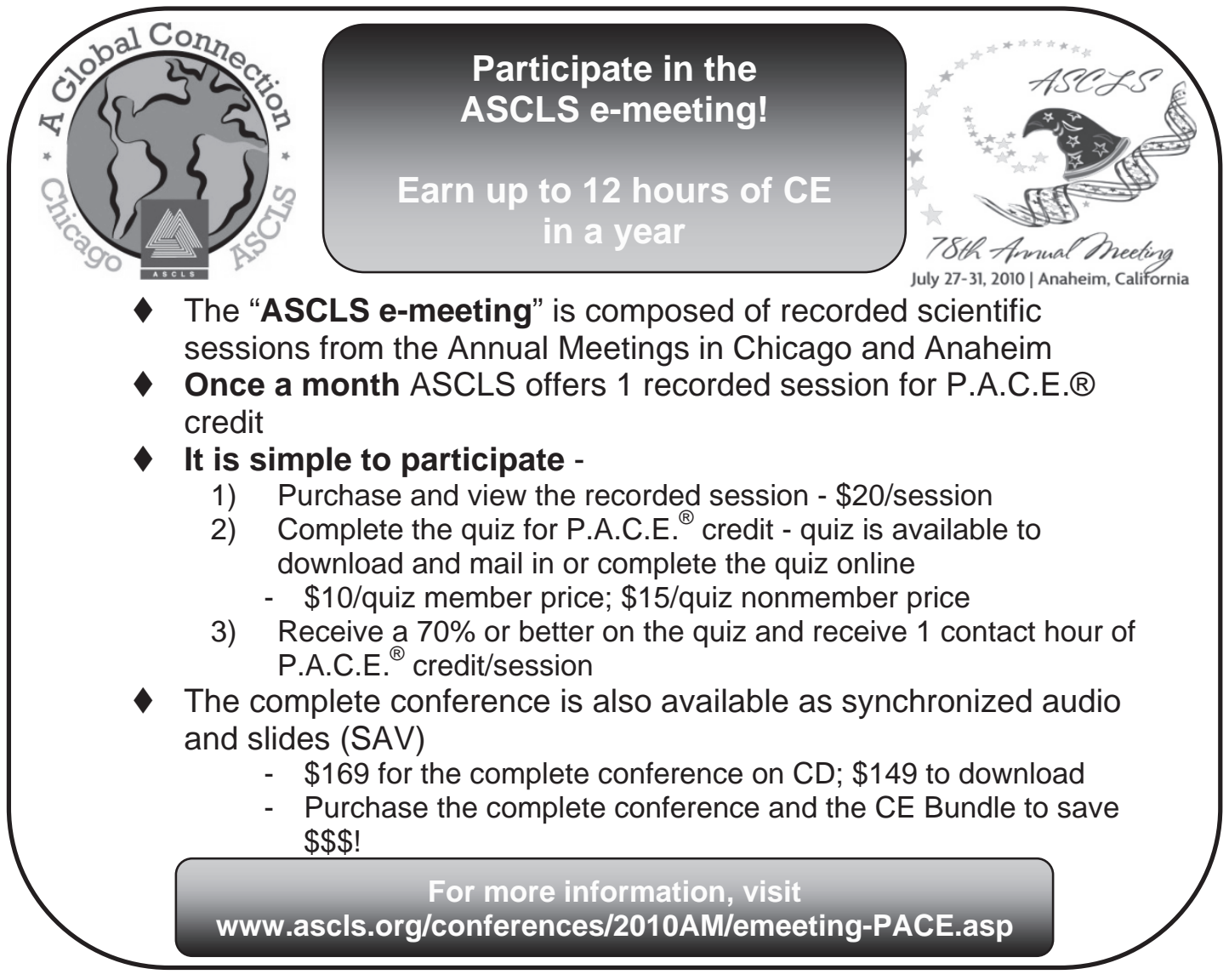

